ESTUDOS RBE?

\title{
Universidade e movimentos sociais no Brasil: uma experiência de ação afirmativa
}

Waldemar Marques

Fernando Silveira Franco

Marcelo Nivert Schlindwein

\section{Resumo}

Apresenta e discute a experiência de um curso de Agronomia voltado para assentados da reforma agrária no Estado de São Paulo, enquanto "ação afirmativa", em desenvolvimento pela Universidade Federal de São Carlos (UFSCar), Campus Sorocaba. Expõe os principais aspectos teóricometodológicos que orientaram a elaboração da proposta do curso, focada na agricultura familiar, a partir de um paradigma de produção sustentável, que preserva o meio ambiente. Destaca a participação dos movimentos sociais do campo na discussão e implementação do curso e relata alguns impactos deste. Considera o curso um indicador de que a universidade pública gratuita e de qualidade pode atender às camadas mais baixas da população, em vez de se limitar às camadas média e alta, como vem ocorrendo historicamente no Brasil.

Palavras-chave: educação no campo; movimentos sociais; agroecologia; reforma agrária; Pronera. 


\section{Abstract \\ Social movements and university in Brazil: an affirmative action experience}

This article presents and discusses an agronomy course focused on agrarian reform developed by São Carlos Federal University (UFSCar) in São Paulo state. The paper shows the main theoretical and methodological aspects that guided the course focused on familiar agriculture from sustainable production paradigm that preserves the environment. It highlights the countryside social movements, the course implementation and some results. The analysis considers this experience as an indicator that the public university can serve the grassroots classes instead of upper-middle class as it occurs in Brazil.

Keywords: field education; social movements; agrarian reform; agroecology; Pronera.

Embora seja um tema de grande amplitude e complexidade, este artigo se ocupará de um caso que sinaliza os novos rumos que estão (ou poderão estar) se abrindo diante da universidade no Brasil. Destacamos aqui os significados de universidade e de movimentos sociais e o abismo que na história do País separa ambos. Recorrendo à história, buscamos o sentido sociológico e político do processo de constituição de uma sociedade extremamente desigual, como é a brasileira, em que a educação superior e a cidadania caminham à distância.

\section{Educação superior e sociedade no Brasil}

A ideia de universidade germina na Grécia antiga, onde a educação superior constituía privilégio de poucos, os grandes proprietários de terras e de escravos. Para essas elites, o tempo do ócio é o mesmo que propicia o cultivo tanto das artes, da literatura, do esporte e da oratória quanto da filosofia e do pensamento abstrato, matrizes da ciência moderna; também é esse mesmo tempo que cria os meios para o exercício da governança por parte dessas elites. A aprendizagem e a prática dos ofícios do comércio e do artesanato e o cultivar a terra não eram afazeres que diziam respeito à elite, aos poderosos. Ao atravessar a Idade Média, quando surgem as universidades, e chegando aos tempos modernos, a educação superior continua privilégio das camadas superiores; nem mesmo a emergência das modernas democracias chegou a alterar essa trajetória. 
Apesar de esse ser um quadro esquemático, ainda assim permite evidenciar um fato social que a sociologia vem reiterando, a exemplo de Bourdieu e Passeron, e que se refere ao quanto a educação está presa à estrutura de classes, de poder, qualquer que seja o tempo histórico, qualquer que seja a sociedade. Para esses autores, na sociedade atual "as classes sociais [são] caracterizadas, sob o aspecto da eficácia da comunicação pedagógica, pelas distâncias desiguais em relação à cultura escolar e por disposições diferentes para reconhecê-la e adquiri-la." (Bourdieu; Passeron, 1975, p. 113).

No Brasil, como já apontara Sérgio Buarque de Holanda (2006, p. 126-128, 169-171) no clássico Raízes do Brasil, a educação superior tem início cerca de dois séculos depois de ocorrer com as colônias espanholas. Cursos de Direito, Medicina e Engenharia só vieram a existir em nosso País a partir do século 19, como resultado da vinda da família real portuguesa, acossada pelas tropas de Napoleão. Mesmo assim, mais do que o preparo para o exercício das profissões "liberais", tais cursos funcionavam como condição para acesso a cargos públicos que garantiam segurança financeira, além de prestígio social. A esses cursos acorriam, sobretudo, filhos dos grandes proprietários rurais, que além de elite econômica constituíam também a elite política, detentora do poder.

Em uma conferência pronunciada no Clube de Engenharia, publicada na Revista Brasileira de Estudos Pedagógicos em 1957, Anísio Teixeira apresenta um quadro da educação brasileira que nos auxilia muito a compreender o que se passa hoje, embora transcorrido mais de meio século. No período de nossa história que vai da Proclamação da República à Revolução de 30, Teixeira (1957, p. 16-17) assinala que "o sistema educacional da elite brasileira [...] era um sistema particular de ensino secundário, de caráter acadêmico e intelectualista, [...] seguido das grandes escolas de profissões liberais, estas, em sua maioria, públicas e gratuitas. Para o povo, havia uma certa quantidade de lugares nas escolas primárias públicas, de onde poderia estes poucos alunos dirigir-se às escolas normais e técnico-profissionais, estas mantidas, em quase totalidade, pelo poder público e, portanto, gratuitas". E conclui: "Com estas escolas, por assim dizê-lo, populares, o Estado reconciliava a sua consciência democrática, ferida pela gratuidade do ensino superior, destinado quase exclusivamente à elite."

$\mathrm{Na}$ análise que se segue nesse artigo, Anísio Teixeira destaca a necessidade de se construir uma educação básica de qualidade extensiva a toda a população, de modo a atender às demandas de uma nova sociedade industrial que se impunha, em contraposição à sociedade agrária brasileira tradicional. Não é isso que o autor vai constatar decorrido um quarto de século no País, após a Primeira República. As demandas para "atender aos filhos dos 'pobres envergonhados' em que se transformou a elite rural do país" (Teixeira, 1957, p. 20-21), bem como as novas camadas médias urbanas, criaram fortes pressões para a expansão do ensino superior gratuito, justamente para os filhos das famílias que tinham condições de pagar por tal estudo, em detrimento de uma educação básica de caráter democrático que viesse atender à população em geral. Num período de oito 
anos, do final da década de 40 e metade de 50, a cota para as despesas com o "ensino elementar" diminuiu, enquanto a cota destinada ao ensino superior mais que dobrou. Para Teixeira (1957, p. 19), isto demonstra "a exacerbação da tendência [...] de buscar a classe superior do País obter a sua educação à custa dos cofres públicos", levando com ela, a partir desse período da história, a "classe média".

As grandes mudanças por que passou o País a partir de então resultaram no Brasil de hoje, uma sociedade urbana e industrial. Contudo, no alvorecer do século 21, Pochmann e Amorin (2003, p. 9), no Atlas da Exclusão Social no Brasil, sustentam, a partir de indicadores construídos com base em dados oficiais, que "século após outro, décadas e mais décadas e o problema da exclusão social no Brasil continua presente, a despeito de sua gravidade e das suas consequências para grande parcela da população brasileira." A industrialização ocorrida dentro de "um padrão imitativo de consumo" não foi capaz de superar a dependência e "terminou por reforçar o elitismo e a exclusão social". As grandes propriedades rurais, outrora latifúndios muitas delas, transformaram-se no "agronegócio" igualmente monocultor e voltado para o mercado externo. Afirmam os autores (2003, p. 21) que no "mapa-síntese da geografia nacional de exclusão social [...] sobressai a constatação de que, ao longo do território do quinto maior país do mundo, há alguns 'acampamentos' de inclusão social em meio a uma ampla 'selva' de exclusão que se estende por praticamente todo o espaço brasileiro." Contudo, esses 'acampamentos' de inclusão localizados sobretudo na região centro-sul, "mais do que um sinal de progresso, são a marca do 'esgarçamento' do tecido social" (Pochmann; Amorin, 2003, p. 26). De sorte que, concluem os autores, ao iniciar um novo milênio, "o Brasil continua a se equilibrar sobre uma frágil base como nação".

Chegamos a 2011 como a sétima economia do planeta. Nesse período, vivemos por quase um quarto de século sob um governo militar, cujos sinais ainda hoje se fazem sentir, não obstante decorrido quase igual período de governo democrático. Nessa mesma época, o índice de Gini, utilizado para medir a distribuição de riqueza, aponta o Brasil como uma das sociedades de maior concentração de riquezas no planeta, num valor nunca abaixo de 0.50, persistente em diferentes décadas. Igualmente, a concentração da propriedade fundiária atravessa decênios num valor nunca inferior a 0.80, em que 1.0 indica a concentração absoluta. É um indicador quantitativo que, contudo, exprime baixa qualidade de vida de grandes contingentes da população brasileira que se espremem nos cubículos das metrópoles urbanas ou nas tendas improvisadas como residências nos acampamentos dos sem-terra.

Da mesma forma, as mudanças no ensino superior também foram enormes. Dias Sobrinho e Brito (2008, p. 487-507) delineiam um quadro atual preciso desse nível de ensino no Brasil e constatam o enorme crescimento a partir dos anos 70, destacando que ele vem dando-se, sobretudo, com o setor privado, mediante a multiplicação de instituições isoladas, tendendo atualmente a um processo de concentração, formação 
de grandes conglomerados empresariais voltados ao ensino superior, com operações na bolsa de valores; esse nível de ensino se transforma progressivamente, no Brasil, em mercadoria. Amplia-se enormemente a matrícula, principalmente nos cursos noturnos, abrindo passagem para o ensino superior a estudantes de estratos socioeconômicos mais baixos da população brasileira. Em pouco mais de uma década, entre 1996 e 2008, a matrícula nesse nível de ensino mais que triplicou: de 1.868.529 para 5.808.017. Não obstante o crescimento do ensino superior no Brasil, dificilmente poderíamos afirmar que essas mudanças tenham alterado substancialmente o quadro traçado por Anísio Teixeira há mais de meio século, sobretudo no aspecto referente a quem tem acesso a esse nível de ensino. A universidade pública gratuita, com qualidade de ensino, ainda constitui a forma privilegiada de ingresso de estudantes oriundos dos estratos médios e altos da população brasileira, principalmente em relação aos cursos que permitem alcançar as posições de maior prestígio, renda e poder nas hierarquias ocupacionais do mundo do trabalho.

\section{Movimentos sociais do campo no Brasil e pressão por educação superior}

Numa outra linha paralela à evolução da educação em nosso País, está a história dos movimentos sociais. Rocher (1971, p. 38) entende como "movimento social uma organização nitidamente estruturada e identificável, que tem como finalidade explícita agrupar membros em vista da defesa ou da promoção de certos objetivos precisos, geralmente com uma conotação social." Caracteriza-se pelo seu caráter reivindicativo, pelo sentimento de exclusão ou necessidade de afirmação referente a questões importantes assim consideradas pelos participantes do movimento. Na história do Brasil, tais movimentos foram e continuam a ser manifestações de uma sociedade excludente, que coloca à sua margem grandes contingentes, privando-os dos benefícios gerados socialmente. Para citar exemplos significativos dos movimentos sociais no Brasil, recorrendo a Queiroz (1965, p. 203-219, 246-260), vamos localizar no início da Primeira República dois acontecimentos de notável expressão política na história do País, em duas regiões opostas do ponto de vista geográfico, bem como, e, sobretudo, do ponto de vista econômico. No interior da Bahia, assistimos à Guerra de Canudos, que aniquila a comunidade liderada pelo místico Antônio Conselheiro, a pretexto de constituir ameaça à República. Cerca de meia década depois, na divisa do Paraná com Santa Catarina, a Guerra do Contestado esmaga um movimento de natureza religiosa cujos integrantes constituíam em grande parte, como no caso anterior, os deserdados da República há pouco inaugurada.

Com o desenvolvimento urbano e a industrialização, movimentos operários e, posteriormente, estudantis entram em cena numa atuação crescente de pressão sobre o Estado, que vem a culminar no golpe militar 
de 1964; na base de todos esses fatos está a exclusão social, marca da sociedade brasileira. Passado o período do governo militar, ressurgem com força os movimentos sociais.

Embora a sociedade brasileira tenha se firmado como uma sociedade urbano industrial, surgem os movimentos sociais dos excluídos da terra, especialmente o Movimento dos Trabalhadores Rurais sem Terra (MST), que apresenta grande estruturação com um forte quadro de lideranças. Não só a pressão pelo acesso à terra constitui motivo de luta deste movimento, mas também a pressão por educação. A ele se agregam outros movimentos sociais do campo, tais como: Federação dos Trabalhadores da Agricultura Familiar do Estado de São Paulo (FAF), Federação dos Empregados Rurais Assalariados do Estado de São Paulo (Feraesp) e Organização das Mulheres Assentadas e Quilombolas do Estado de São Paulo (Omaquesp).

Pode-se dizer, portanto, que, no atual cenário das forças sociais que definem (ou contribuem para definir) os rumos da educação no Brasil, novos protagonistas entraram em cena: os movimentos sociais do campo. No ensino superior, essa presença, por que não dizer pressão, se faz sentir junto a universidades públicas. Geografia, Pedagogia e Agronomia são alguns exemplos de cursos em andamento atualmente no Estado de São Paulo cujos estudantes são assentados da reforma agrária.

Um caso especial reflexo dessa pressão dos movimentos sociais do campo sobre a universidade é o curso de Agronomia com ênfase em Agroecologia em Sistemas Rurais Sustentáveis, atualmente em andamento na Universidade Federal de São Carlos, no Campus de Sorocaba. Caso especial, porque esse tipo de curso tem um custo elevado, caracterizado como um dos bastante demandados pela "classe média" urbana na sua trajetória pela busca de formação superior. É uma experiência que traz sentido emblemático de um rumo diferenciado que pode estar se iniciando para a universidade pública brasileira: receptividade a outras camadas da população excluídas da educação de qualidade, da educação superior. Tal mudança que se vislumbra é algo que se soma à política de ações afirmativas implementada pelo governo federal nos últimos anos, que objetiva assegurar oportunidade de acesso à universidade de estudantes oriundos da população negra, indígena e, no caso, dos assentados da reforma agrária.

Dado o forte significado político e educacional deste curso de Agronomia destinado a assentados da reforma agrária, procuraremos apresentar com certo detalhe o processo de construção da proposta pedagógica e de gestão, bem como os aspectos principais que definem essa proposta como inovadora, os quais são: como nasceu a proposta; a agricultura e o meio ambiente; a agricultura familiar no Brasil; em busca de uma nova proposta de agricultura sustentável; o marco conceitual da agroecologia; a proposta pedagógica do curso de Agronomia para os assentados; as formas de gestão e acompanhamento do curso; e, finalmente, os impactos deste. 


\section{Histórico do curso de Agronomia para assentados da reforma agrária}

A proposta deste curso nasceu do Seminário Universidade e Reforma Agrária, em junho de 2006, realizado pela Pró-Reitoria de Graduação da Universidade Federal de São Carlos (UFSCar), do qual participaram representantes dos movimentos sociais do campo no Estado de São Paulo, sendo eles: Movimento dos Trabalhadores Rurais sem Terra (MST), Federação dos Trabalhadores da Agricultura Familiar do Estado de São Paulo (FAF), Federação dos Empregados Rurais Assalariados do Estado de São Paulo (Feraesp) e Organização das Mulheres Assentadas e Quilombolas do Estado de São Paulo (Omaquesp), bem como Instituto Nacional de Colonização e Reforma Agrária (Incra), Regional de São Paulo, órgão responsável pelo Programa Nacional de Educação na Reforma Agrária (Pronera). Decidiu-se pela efetivação de dois cursos: Pedagogia e Agronomia, realizados, respectivamente, em São Carlos e no Campus de Sorocaba. Merece destaque a participação dos movimentos sociais nas discussões que definiram os princípios, os objetivos e as bases metodológicas e de gestão do curso.

O curso de Agronomia busca oferecer qualificação profissional diferenciada que contemple a interação entre as atividades de ensino, pesquisa e extensão e maior integração entre a UFSCar e o universo dos agricultores familiares assentados no Estado de São Paulo. A proposta leva em consideração as características e especificidades ecológicas e edafoclimáticas e a realidade sociocultural e econômica dos assentamentos. A delimitação, abrangendo apenas o Estado de São Paulo, atendeu à demanda dos movimentos sociais.

O curso foi concebido de forma a garantir a formação de agrônomos com um perfil profissional que os habilite a analisar criticamente as situações e a repensar as formas de interação da agricultura com a realidade na qual está inserida, com ênfase no segmento da agricultura familiar, contribuindo para a equidade na distribuição da renda, a valorização das culturas locais e o respeito ao meio ambiente.

Poucos são os esforços na formação de profissionais com um conteúdo técnico-científico que trabalhe com a perspectiva da construção de um novo modelo de desenvolvimento agrícola sustentável, no âmbito dos sistemas produtivos individualmente, das comunidades e das organizações representativas da agricultura familiar.

\section{O marco referencial da agroecologia}

A elaboração da proposta do curso se deu a partir da problematização da agricultura contemporânea, que está vivenciando uma crise sem precedentes, pois a forma pela qual tem sido orientada acarreta sérios impactos sociais e ambientais em âmbito mundial. O problema mais preocupante atinge países como o Brasil, também considerado país "emergente", devido à transferência linear para as regiões tropicais e 
subtropicais de um padrão tecnológico com uso de capital intensivo, gerado para realidades temperadas e frias.

Entre os problemas creditados ao setor agrícola em países como o Brasil, estão o aumento da dependência e a perda de eficiência energética, o desflorestamento e a perda de biodiversidade, a redução da variabilidade genética e a susceptibilidade às pragas das espécies melhoradas para altas produtividades, as doenças e os estresses ambientais, a degradação dos recursos florestais e edáficos pelo manejo inadequado, os desequilíbrios biológicos e ecológicos resultantes da monocultura e do uso de agroquímicos, a poluição do ambiente, dos alimentos e do ser humano por agrotóxicos e, finalmente, a concentração de terra, renda e meios de produção com a desigual apropriação da riqueza gerada pelo setor.

Tal situação tem motivado a busca de novos entendimentos e concepções na investigação agronômica e na condução dos processos produtivos agrícolas, por meio de enfoques e métodos mais abrangentes que propiciem o entendimento do todo, campo em que se insere a abordagem sistêmica, holística, a busca da inter e da transdisciplinaridade. Trata-se, pois, da construção de outro referencial técnico-científico enquanto base para ação.

O que se vem tornando cada vez mais claro é que um referencial conceitual e analítico cartesiano e reducionista se mostra limitado e insuficiente na determinação das causas e na identificação das alternativas de superação dos crescentes problemas produtivos agrícolas e dos impactos negativos gerados pelo setor. Nessa esfera, a agroecologia pode dar uma expressiva contribuição enquanto uma área da ciência que utiliza referencial teórico e conceitual fundamentado na abordagem sistêmica, buscando entender e analisar a agricultura como um todo (Altieri, 1989, p. 42).

A agroecologia é definida como:

\begin{abstract}
A disciplina científica que enfoca o estudo da agricultura sob uma perspectiva ecológica e com um marco teórico cuja finalidade é analisar os processos agrícolas de forma abrangente. O enfoque agroecológico considera os ecossistemas agrícolas como as unidades fundamentais de estudo; e, nestes sistemas, os ciclos minerais, as transformações de energia, os processos biológicos e as relações socioeconômicas são investigadas e analisadas como um todo. (Altieri, 2004, p. 23).
\end{abstract}

Assim, a agroecologia requer um enfoque sistêmico, que é uma decorrência e ao mesmo tempo faz parte dessa nova visão que se pretende construir a respeito da agricultura. Um sistema pode ser definido como um "conjunto de componentes físicos, um conjunto ou coleção de coisas, unidas ou relacionadas de tal maneira, que formam e atuam como uma entidade, um todo" (Becht, 1974, p. 579). Tal conceito embute dois aspectos fundamentais a qualquer sistema que se pretenda estudar: estrutura e função. A primeira está relacionada com o arranjo dos componentes do sistema e a segunda com a atuação dele. A função de um sistema sempre se define em termos de processos e está relacionada com o de receber entradas e produzir saídas (Gliessmann, 2000, p. 343). A noção 
fundamental é a totalidade do sistema e também o complexo dos fatores físicos formando o que chamamos de bioma, em sentido lato, os fatores do habitat. Os sistemas assim formados, do ponto de vista da ecologia, são as unidades básicas da natureza na superfície terrestre.

A par da problemática da agricultura em geral, a agricultura convencional nos trópicos configura uma conjuntura em que a degradação socioambiental se tornou evidente. Em decorrência disso, a preocupação com a sustentabilidade passou a ocupar lugar central nos debates contemporâneos, assim como a busca de alternativas que propiciem a superação das desigualdades sociais e da degradação dos recursos naturais.

$\mathrm{Na}$ realidade brasileira, o sistema educacional vigente, em geral, oferece uma formação profissional voltada ao atendimento de um mercado de trabalho determinado pelo padrão tecnológico hegemônico e pelos segmentos empresariais e comerciais. Nesse círculo vicioso, os agricultores estão cada vez mais inseridos em um processo de relações de troca bastante desigual com os capitais industrial, comercial e financeiro, de forma subordinada, resultante do modelo tecnológico hegemônico, que amplia a dependência da agricultura de energia externa.

A partir do final da Segunda Guerra Mundial, e de forma mais expressiva com o advento da chamada "Revolução Verde", o setor produtivo agropecuário de muitos países sofreu transformações estruturais expressivas. Tal orientação busca o aumento da produção e da produtividade por meio da manipulação genética e da artificialização do processo produtivo pelo uso de agroquímicos (fertilizantes de síntese e agrotóxicos) e energia externa, desprezando-se os saberes historicamente acumulados pelos agricultores. Estes adequaram seus sistemas produtivos a cada realidade específica local, adaptando-os a condições adversas, mediante um processo empírico de tentativa e erro, gerando sistemas de cultivo que permitiram o crescimento das populações e o desenvolvimento de sociedades complexas segundo a disponibilidade de recursos locais.

Particularmente no âmbito da agricultura familiar, esses impactos foram expressivos: concentração de renda em detrimento do pequeno produtor, redução significativa das ocupações no campo com a intensificação da mecanização dos processos produtivos, queda do preço dos produtos recebido pelo agricultor e crescente endividamento do produtor e, por fim, a evasão da grande maioria dos jovens do meio rural.

A agricultura familiar tem grande importância no cenário socioeconômico brasileiro, por sua capacidade tanto de absorção de mão de obra como de produção, especialmente de alimentos básicos. No início desta década, cerca de $85 \%$ das propriedades rurais do Brasil pertenciam a famílias. Existiam mais de 4,5 milhões de estabelecimentos agrícolas familiares no País, envolvendo um universo de 13,8 milhões de pessoas. Esses estabelecimentos produziam mais de $60 \%$ dos alimentos consumidos no Brasil, empregavam 77\% do total de pessoal ocupado na agricultura e eram responsáveis por 38\% do valor bruto da produção agropecuária nacional.

Se, de um lado, a agricultura convencional tende a produzir a insustentabilidade, de outro, os assentamentos de reforma agrária que 
não redefinirem suas estratégias de organização da produção estarão caminhando nessa mesma direção. Isso reforça a necessidade de uma política educacional voltada para a qualificação específica em agroecologia e sistemas rurais sustentáveis.

Focalizando nossa atenção nos assentamentos de reforma agrária existentes hoje no Estado de São Paulo, temos o seguinte quadro: no início de 2007, a reforma agrária estava presente em 76 municípios desse Estado, com 209 projetos de assentamentos instalados em diversas regiões e em diferentes estágios de desenvolvimento. Ao todo, são 12.457 famílias vivendo em assentamentos, o equivalente a mais de 43 mil pessoas, entre homens, mulheres, jovens e crianças, que, além da possibilidade de inserção social e exercício da cidadania, passaram a contribuir para o desenvolvimento rural desse Estado. As famílias assentadas em projetos criados e administrados pelo Incra - em áreas desapropriadas, públicas da União ou adquiridas pelo Decreto no 433/1992 - e pela Fundação Instituto de Terras do Estado de São Paulo (Itesp) - em áreas devolutas e públicas estaduais - estão, em sua maioria, na região de Pontal e Araçatuba (45\% e 18\%, respectivamente) (Brasil, 1992).

Com a comprovação da insustentabilidade do padrão tecnológico atual, novos marcos conceituais e operacionais passaram a ser construídos, visando melhor clarear e fundamentar propostas que apontem para a consecução de processos de produção agrícola sustentáveis. Tal construção tem ocorrido na esfera dos conceitos, das diretrizes, dos objetivos e dos princípios, buscando abranger as dimensões social, ecológica, energética e econômica da sustentabilidade (Altieri, 1989, p. 207).

O quadro aqui delineado da agricultura familiar e o novo paradigma da sustentabilidade que necessariamente deverá orientar as práticas produtivas colocam a necessidade de formação de profissionais capazes de atuar nessa direção, ou seja, estabelecem a demanda de formação de um profissional com outro perfil.

O perfil do profissional que tomamos como referência segue aquilo que a UFSCar (2008) define no seu documento "Perfil do Profissional a ser formado na UFSCar", coerente com as mudanças e o ritmo destas nas sociedades contemporâneas. Nesse sentido, ele deve ser uma pessoa "capaz de aprender de forma autônoma e contínua" (UFSCar, 2008, p. 5), articulado com as fontes geradoras de pesquisas e informações. Talvez seja essa a marca mais proeminente do profissional nos dias de hoje, qualquer que seja sua área de atuação. Aspectos mais específicos desse perfil indicam que esse indivíduo deve estar apto a "produzir e divulgar novos conhecimentos, tecnologias, serviços e produtos" (p. 7), bem como "empreender formas diversificadas de atuação" (p. 9), agindo "inter/ multi/transdisciplinarmente" (p. 11), rompendo barreiras que isolam o saber profissional.

Esse perfil destaca uma dimensão fortemente ética do agir profissional ao sinalizar que "deve pautar-se na ética da solidariedade enquanto ser humano, cidadão e profissional" (p. 17), buscando "maturidade, sensibilidade e equilíbrio ao agir profissionalmente" (p. 19). Trata-se de formar 
um indivíduo que não apenas atenda às demandas socioprofissionais da sociedade brasileira, com ênfase nas áreas de reforma agrária, mas também caudatário de valores que estão na base da construção de uma sociedade democrática e mais justa. Como tal, deverá atuar tendo como horizonte maior de sua ação uma visão planetária de compromisso "com a preservação da biodiversidade no ambiente natural e construído com sustentabilidade e melhoria da qualidade de vida" (p. 13).

Para tanto, esse profissional deverá apresentar um conjunto de competências. Competência (Ramos, 2001, p. 71-89) é aqui definida como "a capacidade real do sujeito para atingir um objetivo ou um resultado num dado contexto", capacidade de enfrentamento de "situações e acontecimentos próprios de um campo profissional". A noção de competência refere-se a conhecimentos que "não se limitam ao nível de sua aplicabilidade" e pressupõe, também, "um exercício reflexivo" em "que o sujeito mobilize suas aprendizagens em favor das situações" e seu enfrentamento, ou seja, tais competências deverão expressar um conjunto de conhecimento tecnológico de forte base científica.

\section{Matriz curricular do curso de Agronomia para assentados da reforma agrária}

Os grupos de conhecimentos discriminados a seguir abrangem o que está sendo considerado neste curso de Agronomia como o repertório básico para que o estudante desenvolva, ao longo de sua formação, as competências e habilidades previstas.

Esses conhecimentos encontram-se organizados em cinco grupos conceituais e em um grupo de atividades integradoras: Ciências da Natureza e Matemática; Ciências Humanas; Recursos Naturais; Produção Animal, Vegetal e Agroecologia; Engenharia Agrícola e Tecnologias; Atividades Integradoras.

Segue abaixo a caracterização de cada um desses grupos, destacando as questões/conteúdos que devem contemplar dentro da proposta pedagógica e a relação das disciplinas componentes de cada um.

\section{Ciências da Natureza e Matemática}

Estão relacionadas a diferentes áreas do conhecimento cujos conteúdos abordarão aspectos/questões básicas indispensáveis para a apropriação e produção dos saberes necessários à formação do agrônomo. Fazem parte deste grupo de conhecimento disciplinas/atividades curriculares cujos conteúdos se relacionam à física, química, matemática e biologia. A partir desses conteúdos, os estudantes deverão se apropriar de um conjunto de conhecimentos e práticas que subsidiam e fundamentam a compreensão de outros fenômenos e processos que configuram a especificidade da área de agronomia e que pressupõem outras abordagens científicas. Este conjunto 
de disciplinas funciona como uma introdução aos elementos conceituais e metodológicos, base de todo e qualquer conhecimento científico.

\section{Ciências Humanas (CH)}

A área de Ciências Humanas, com especial destaque a socioeconomia, tem como objetivo contribuir para a formação do estudante no que se refere às dimensões sociopolíticas e econômicas de sua prática profissional e inclui questões básicas da filosofia da ciência trabalhadas numa perspectiva desmistificadora do conhecimento científico, reconhecendo as inter-relações existentes entre ciência, tecnologia e sociedade. Aspectos cruciais da sociologia possibilitarão o reconhecimento das especificidades da organização sociopolítica e das relações de poder e dominação no meio rural. Este conjunto de disciplinas deverá habilitar o estudante a desenvolver uma reflexão teórica do processo histórico, para elaboração de uma matriz de análise socioeconômica e política determinante na interpretação da dinâmica atual do modo de produção capitalista, bem como desenvolver cenários e análises de conjuntura socioeconômica e política. Parte-se da premissa de que o processo de construção da sustentabilidade do assentamento de reforma agrária passa também pela apropriação das ferramentas de gestão utilizadas pelas empresas na atualidade, que devem contemplar adaptações necessárias à realidade das pequenas produções rurais, indo além da produção familiar voltada para a subsistência e buscando profissionalizar as famílias assentadas para produção fortemente voltada ao mercado consumidor. Tem-se como meta apoiar, em termos práticos, os agricultores quanto à diferenciação, diversificação e agregação de valor, industrialização e comercialização direta dos produtos e serviços, formação de grupos informais, associações e cooperativas, organização de cadeias produtivas solidárias e formação de redes de cooperação. Este conjunto de conhecimentos contribui, também, para melhores relações interpessoais.

\section{Recursos Naturais (RN)}

Neste eixo de conhecimentos, são analisados os fatores bióticos e abióticos que compõem as paisagens e o ambiente, mediante metodologias e práticas de interpretação desse ambiente a partir de seus principais componentes estruturantes. Dentro do conjunto de disciplinas propostas, são apresentados dois blocos interdependentes: I) Disciplinas de Diagnose e Práticas Metodológicas, que têm como meta capacitar os alunos na interpretação dos aspectos básicos que constituem a paisagem agrícola e a experimentação de métodos de análise desses diferentes componentes e suas inter-relações; e II) o bloco referente a Disciplinas envolvendo Manejo e Conservação, nas quais serão apresentadas teorias que habilitam o aluno a discutir de forma crítica e propor projetos e programas de manejo e conservação nos ambientes agrícolas. 
Este bloco de disciplinas abrange as temáticas relativas à produção vegetal e animal, orientadas segundo os princípios agroecológicos, na perspectiva da sustentabilidade em tal atividade antrópica. Trabalhar-se-ão os conhecimentos e os princípios da ecologia passíveis de ser apropriados na condução dos agroecossistemas, as estratégias de manejo e conservação dos recursos naturais que prescindam da técnica, os processos e insumos agressivos ao ambiente e ao ser humano e a condução dos sistemas produtivos com base nas distintas realidades ecológicas e socioeconômicas, em suas dimensões vegetal e animal.

\section{Engenharia Agrícola e Tecnologias (EAT)}

Tal campo reúne as disciplinas afins às temáticas relativas aos campos da engenharia que são demandados na condução da produção agrícola, nas esferas da mecânica, construções, benfeitorias e instalações, eletricidade, hidráulica e obras de infraestrutura. Integra também tal escopo a disciplina de recuperação de áreas degradadas.

\section{Integradoras (INT)}

O eixo destas disciplinas constitui um dos mais importantes elementos didático-pedagógicos do projeto na busca de uma formação integrada, na perspectiva do conhecimento em rede. Elas ajudarão a efetivar o uso da pesquisa como norteadora do curso. Nesse processo, partindo da realidade local dos assentamentos, os estudantes terão elementos para aprofundar a reflexão e a sistematização no desenvolvimento da monografia, uma das principais ferramentas de avaliação do curso. As disciplinas deste eixo foram estruturadas de modo a permitir o diálogo com os conteúdos específicos na elaboração e discussão coletiva de ferramentas, metodologias e referenciais teóricos usados na construção da pesquisa e na apresentação dos seus resultados. Para tanto, trabalha-se inicialmente com elementos básicos que levam a essa sistematização, como a Leitura e Produção de Textos e os enfoques sistêmico e dialético dentro da Metodologia de Pesquisa; o diagnóstico do contexto e a apresentação de resultados parciais nos seminários coletivos; a Leitura e Produção de Textos Científicos num estágio mais avançado; e a consequente apresentação da monografia final estruturada nos seminários coletivos.

\section{Abordagem metodológica do curso}

Concebida a proposta de curso a partir da realidade já referida e do paradigma de sustentabilidade, uma nova abordagem metodológica se 
impõe para o desenvolvimento do curso. O marco metodológico mencionado abrange duas dimensões distintas, mas que se completam: a dimensão pedagógica e a dimensão da gestão do curso.

\section{- Dimensão pedagógica}

A dimensão pedagógica se fundamenta numa abordagem construtivista, que revela todos os participantes de um processo pedagógico como sujeitos atuantes, que têm conhecimentos, são capazes e se educam mutuamente. Embora com papéis específicos e diferenciados, professores, estudantes, organizações ou comunidades educam-se num processo coletivo de construção, troca e aquisição de conhecimentos, a partir do que cada um já sabe e do conhecimento científico já sistematizado, em diálogo com as práticas cotidianas dos próprios sujeitos.

Em todos os tempos e espaços, serão envidados esforços na concretização de uma abordagem na qual os diversos conhecimentos dialoguem e os sujeitos qualifiquem sua práxis. Embora tenham características específicas, esses tempos e espaços estão inter-relacionados e têm um papel importante no desenvolvimento de projetos que contribuam para as evoluções individual e social do estudante, as quais se condicionam mutuamente, e de suas comunidades de origem.

Além das atividades presenciais, o estudante desenvolverá - sempre mediante orientação - diagnósticos, pesquisas, elaboração e execução de projetos em sua propriedade e/ou comunidade, nos quais serão orientados, acompanhados e avaliados pelos professores, monitores e colaboradores da iniciativa.

O curso possibilitará aos participantes estudar, pesquisar e desenvolver projetos e práticas que lhes permitam o domínio de fundamentos, princípios e bases científicas seguras para atuarem em diferentes instâncias: nos sistemas produtivos, nas comunidades e organizações da agricultura familiar (grupos, associações, cooperativas e sindicatos) e no campo das políticas públicas.

Visando atingir o perfil profissional desejado, esse projeto adota uma estrutura curricular que viabiliza uma relação permanente entre instituição de ensino, educando e comunidade, articulando (e valorizando) o saber acadêmico historicamente acumulado com o saber popular e empírico dos sujeitos locais.

As ações de ensino serão desenvolvidas na perspectiva da interdisciplinaridade, articuladas com as atividades de pesquisa e extensão, numa concepção de construção do conhecimento em "rede", em que a disciplina é um ponto constitutivo dessa rede, não um fim em si mesma.

Uma estratégia a ser adotada, visando à integração de atividades de ensino, pesquisa e extensão, é o regime de alternância, no qual os educandos dedicarão uma parte de seu tempo escolar às atividades didáticas presenciais e outra parte a trabalhos em seus agroecossistemas e/ou junto à sua comunidade de origem, contemplando os aspectos produtivos, tecnológicos e político-organizacionais. 
Como a evolução individual e a grupal se condicionam mutuamente, o aspecto fundamental da metodologia proposta é a garantia de atividades individuais, em pequenos grupos e em grupos maiores para estudo, elaboração, pesquisas e práticas. Essas atividades complementares são importantes frente à orientação desejada na construção e organização do conhecimento. Os tempos e os espaços coletivos possibilitam a troca, o debate, o contraditório, a interação, a cooperação e o exercício da liderança e da democracia.

Os tempos e os espaços individuais possibilitam a reflexão e a observação de fenômenos de interesse particular, o desenvolvimento do potencial pessoal e o processo individual de sistematização e (re)organização dos conhecimentos, o que qualificará ainda mais a participação de cada um no grupo e no processo do curso, desencadeando um círculo virtuoso de aprendizagem.

O papel do curso, nesse sentido, é promover e orientar vivências individuais e grupais, garantindo a inter-relação entre os processos pessoais e coletivos em torno de um projeto pedagógico coerente, que respeite e valorize os saberes individuais e contribua na organização dos diversos conhecimentos do grupo, aprofundando-os, problematizando-os, ampliando-os e reelaborando-os, quando necessário, a partir de bases mais sólidas de conhecimentos.

Esses tempos e espaços diferenciados visam, ao mesmo tempo, garantir o desenvolvimento da individualidade e da coletividade, produzindo comportamentos, atitudes, conceitos e valores importantes para a atuação do futuro profissional que, desde seu ingresso no curso, vivencia a experiência de ser um agente de desenvolvimento sustentável e de atuar cooperativamente, assumindo seu papel no grupo.

Além das atividades presenciais, o estudante é estimulado e orientado na realização de diagnósticos, pesquisas, elaboração e execução de projetos no assentamento, atividades em que serão orientados, acompanhados e avaliados pelos professores, monitores e colaboradores da iniciativa. Deverão ser criadas condições necessárias para que professores acompanhem, periodicamente, os trabalhos dos educandos em seu tempo-comunidade.

Dentro dessa perspectiva, possibilitar-se-á uma relação mais permanente entre instituição de ensino, educando e comunidade, articulando os saberes acadêmicos historicamente acumulados com os saberes populares dos sujeitos locais.

Assume-se, também, o diagnóstico como elemento que introduzirá o estudante na prática do planejamento e da gestão, aspecto a ser abordado de forma recorrente no decorrer do curso.

\section{- Dimensão da gestão do curso}

A outra importante dimensão metodológica do curso refere-se à gestão, lembrando aqui o que determina a Lei de Diretrizes e Bases da Educação 
Nacional (LDB - Brasil, 1996), no seu art. 3º quanto ao princípio de "gestão democrática do ensino público". A coordenação deste curso é feita com base no que define a Portaria GR nº 662/03 (UFSCar, 2003) e nas diretrizes que determinam as atribuições do coordenador e do Conselho de Curso da UFSCar. Essas diretrizes estabelecem uma coordenação colegiada, composta por representantes dos discentes e por professores de diferentes áreas do conhecimento, as quais incluem um leque de disciplinas afins.

Tal coordenação estimula a participação efetiva desses diferentes segmentos, sendo que as reuniões do Conselho de Curso se constituem como um foro de debate referente às questões do curso, promovendo a divulgação de informações, as discussões sobre os objetivos do curso e das disciplinas e a implementação dos planos de ensino, bem como a inter-relação das disciplinas entre si, de modo que a visão de conhecimento como rede se torne operacionalizável.

O Conselho do Curso é composto por cinco docentes e um representante discente por turma, com direito a voto, e pela secretaria da coordenação, sem direito a voto. Cada professor representa um dos seguintes núcleos de conhecimento da Agronomia: Ciências da Natureza e Matemática; Ciências Humanas; Recursos Naturais; Produção Animal, Vegetal e Agroecologia; Engenharia Agrícola e Tecnologias. Os docentes que compõem o Conselho e seus suplentes são indicados por seus pares para mandato de dois anos e os representantes discentes e seus suplentes são eleitos por seus pares para mandato de um ano. O coordenador e o vice-coordenador são eleitos, de forma paritária, por dois conjuntos de votantes, sendo o primeiro formado pelos professores e servidores técnico-administrativos e o segundo pelo pessoal discente; os mandatos são de dois anos.

A Coordenação do Curso se dá também por uma Direção Colegiada composta por 15 membros, sendo cinco docentes da UFSCar, quatro representantes dos discentes, um representante de cada um dos Movimentos Sociais (MST, FAF, Feraesp e Omaquesp) e um do Incra. Essa Coordenação funciona de modo não oficial, como uma estratégia para manter a participação efetiva de diferentes instituições (UFSCar, Incra/Pronera) e movimentos sociais.

Uma equipe de três monitores é responsável pelo acompanhamento dos educandos em seu tempo-comunidade, monitorando-os e orientando-os, em uma ação integradora dos tempos presenciais e comunitários. Os monitores acompanham as atividades presenciais e a construção dos projetos individuais a serem realizados nas comunidades e nos sistemas produtivos, os quais virão a embasar as monografias finais. Cada monitor é responsável por aproximadamente 17 estudantes no tempo-comunidade divididos nas diferentes regiões do Estado, assessorando-os e informando os professores e o coordenador do curso sobre o andamento dos trabalhos de campo.

\section{Andamento do curso e lições aprendidas}

Em março de 2011 o curso alcançou a metade do seu trajeto, previsto para um período de cinco anos. Nesse percurso, muitas dificuldades 
foram e estão sendo enfrentadas: estrutura física, financiamento, formas de gestão acadêmica e outras. Contudo, dentro dos marcos definidos no projeto-pedagógico aqui delineados, alguns aspectos já podem ser apontados como indicadores positivos desse processo. Primeiramente, a desistência pode ser considerada baixa: dos 60 aprovados, decorrida a metade do curso, 9 desistiram, permanecendo hoje uma turma com 51 estudantes; uma taxa de desistência pequena, dadas as condições em que opera o curso - são enormes as dificuldades de transporte dos estudantes, oriundos de todos os pontos do Estado de São Paulo; a especificidade da trajetória escolar desses alunos, muitos deles com precária formação escolar de grau médio; e a infraestrutura de alojamento e alimentação que requer contratação terceirizada de serviços. Acrescente-se a isso o fato de que a frequência às aulas em tempo integral por um período superior a três meses impede que o estudante se dedique ao seu lote de terra, muitas vezes com sérios prejuízos para a manutenção do aluno e de sua família. A persistência do estudante com esse perfil social no curso revela que é possível, dadas as condições de apoio que a universidade deva cumprir, que pessoas que jamais poriam o pé em qualquer curso superior tenham acesso e permanência a uma educação de qualidade.

Outro aspecto que cumpre aqui registrar diz respeito aos impactos do curso. Essa questão deverá receber maior atenção da Coordenação mediante um acompanhamento mais sistemático até o final do curso, quando se completará a trajetória acadêmica do estudante. Contudo, já se podem perceber alguns sinais indicativos desses impactos. Um deles refere-se a um projeto de desenvolvimento de sistemas agroflorestais em desenvolvimento na região do Pontal do Paranapanema, do qual participam estudantes deste curso de Agronomia. São oportunidades de inserção profissional que se abrem para pessoas que, nas condições que configuram a sociedade brasileira atual, de extrema concentração, jamais teriam essas chances. Outro ponto refere-se a projetos de produção e de assistência técnica a comunidades de assentados que estão sendo elaborados por estudantes do curso e deverão iniciar seu desenvolvimento no decorrer deste, continuando após seu término. Do total de 51 estudantes, 10 são bolsistas e estão envolvidos em projetos de ensino, pesquisa e extensão, com o apoio financeiro do Conselho Nacional de Desenvolvimento Científico e Tecnológico (CNPq) e do Programa de Educação Tutorial (PET) do Ministério da Educação (MEC). São projetos que, no seu âmbito, alterarão substancialmente as técnicas e os modelos de produção em busca de uma produção sustentável, baseada no paradigma da agroecologia, articulada a cadeias produtivas que fortaleçam a agricultura familiar.

\section{Considerações finais}

Este curso de Agronomia para assentados da reforma agrária demonstra que é possível que pessoas com uma trajetória social 
diversa daquela que vem constituindo tradicionalmente os discentes das universidades públicas ingressem e permaneçam com qualidade nelas. Esse fato põe em questão o argumento do mérito acadêmico proporcionado pelos vestibulares, o qual tende a confirmar a hipótese de Bourdieu e Passeron sobre a seletividade social, apontando na direção de que as formas de acesso à universidade pública se voltam mais para perpetuar as desigualdades sociais do que para a seleção dos mais competentes. Essa é uma questão polêmica, sem dúvida, que não permite conclusões apressadas. De qualquer modo, a experiência deste curso de Agronomia para assentados da reforma agrária fortalece a convicção de que é necessário repensar e, mais do que isso, redefinir os critérios de acesso ao ensino superior público e as formas de apoio ao estudante. Estaríamos, nesse caminho, retomando a trilha apontada pelo educador Anísio Teixeira na busca da democratização da educação superior. Nesse sentido, é possível perceber que novos rumos estão abrindo-se nessa direção: o poder público está atuando, a universidade pública está movendo-se.

\section{Referências bibliográficas}

ALTIERI, Miguel A. Agroecologia: as bases científicas da agricultura alternativa. Tradução de Patrícia Vaz. Rio de Janeiro: PTA/FASE, 1989. $240 \mathrm{p}$.

Agroecologia: a dinâmica produtiva da agricultura sustentável. Porto Alegre: Editora UFRGS, 2004, 117 p.

BRASIL. Lei no 9.394, de 20 de dezembro de 1996 (LDB). Estabelece as diretrizes e bases da educação nacional. Disponível em: < http://www. planalto.gov.br/ccivil_03/leis/L9394.htm>.

. Decreto $n^{\circ} 433$, de 24 de janeiro de 1992. Dispõe sobre a aquisição de imóveis rurais, para fins de reforma agrária, por meio de compra e venda. Disponível em: < http://www.planalto.gov.br/ccivil_03/ decreto/D0433.htm>.

BECHT, G. Systems theory: the key to holism and reductionism.

Bioscience, v. 24, n. 10, p. 579-596, 1974.

BOURDIEU, Pierre Félix; PASSERON, Jean Claude. A reprodução: elementos para uma teoria do sistema de ensino. Rio de Janeiro: Livraria Francisco Alves, 1975.

COSTA, Manoel Baltasar Baptista da. Estresse ambiental nos trópicos: um problema agravado pelo homem?. In: SIMPÓSIO INTERNACIONAL 
SOBRE ESTRESSE AMBIENTAL, 1995. Belo Horizonte. O milho em perspectiva. Belo Horizonte: Embrapa/CNPMS - CYMMIT/UNDP, 1995. p. 43-49.

DIAS SOBRINHO, José; BRITO, Márcia Regina F. de. La educación superior em Brasil: principales tendencias y desafios. Avaliação: Revista da Avaliação da Educação Superior, Sorocaba, SP: Uniso, v. 13, n. 2, jun. 2008.

GLIESSMAN, Stephen, Agroecologia: processos ecológicos em agricultura sustentável. Tradução de Maria José Guazzelli. Porto Alegre: Editora UFRGS, 2000, 653 p.

HOLANDA, Sérgio Buarque de. Raízes do Brasil. São Paulo: Companhia da Letras. 2006.

POCHMANN, Marcio; AMORIM, Ricardo (Org.). Atlas da exclusão social no Brasil. 2. ed. São Paulo: Cortez, 2003.

QUEIROZ, Maria Isaura Pereira de. O messianismo no Brasil e no mundo. São Paulo: Dominus Editora. 1965.

RAMOS, Marise Nogueira. A pedagogia das competências: autonomia ou adaptação? São Paulo: Cortez, 2001.

ROCHER, Guy. Sociologia geral. Lisboa: Editorial Presença, 1971.

SNYDERS, Georges. Escola, classe e luta de classes. 2. ed. Lisboa, Portugal: Moraes Editores, 1981.

TEIXEIRA, Anísio. A escola brasileira e a estabilidade social. Revista Brasileira de Estudos Pedagógicos, Brasília, v. 28, n. 67, p.3-29, jul./set. 1957.

UNIVERSIDADE FEDERAL DE SÃO CARLOS (UFSCar). Projeto Pedagógico do Curso Especial de Bacharelado em Agronomia com Enfase em Agroecologia e Sistemas Rurais Sustentáveis. Sorocaba, 2010, 87 p.

UNIVERSIDADE FEDERAL DE SÃO CARLOS (UFSCar). Pró-Reitoria de Graduação. Perfil do profissional a ser formado na UFSCar. 2. ed. São Carlos: UFSCar, 2008.

UNIVERSIDADE FEDERAL DE SÃO CARLOS (UFSCar). Portaria $R G n^{\circ}$ 662, de 5 de dezembro de 2003. Dispõe sobre o Regulamento Geral das Coordenações de Cursos de Graduação. Disponível em: < http://www. prograd.ufscar.br/normas/portaria662_031.pdf>. 
Waldemar Marques, doutor em Educação pela Universidade Estadual de Campinas (Unicamp), ex-professor da Universidade Federal de São Carlos (UFSCar) e atual professor no curso de Pós-Graduação em Educação da Universidade de Sorocaba (Uniso).

waldemar.marques@prof.uniso.br

Fernando Silveira Franco, doutor em Ciências Florestais pela Universidade Federal de Viçosa (UFV), é professor adjunto nos cursos de Engenharia Florestal e Biologia da Universidade Federal de São Carlos (UFSCar), Campus Sorocaba, e coordenador do curso de Agronomia com ênfase em Agroecologia e Sistemas Rurais Sustentáveis - Pronera-Incra/ UFSCar.

fernandosf@ufscar.br

Marcelo Nivert Schlindwein, doutor em Ciências Biológicas (Zoologia) pela Universidade Estadual Paulista Júlio de Mesquita Filho (Unesp), é professor adjunto nos cursos de Biologia, Turismo e Agronomia com ênfase em Agroecologia e Sistemas Rurais Sustentáveis - Pronera-Incra/UFSCar, da Universidade Federal de São Carlos (UFSCar), Campus Sorocaba.

mnivert@ufscar.br

Recebido em 20 de abril de 2011.

Aprovado em 29 de outubro de 2011. 